\title{
RPA-coated single-stranded DNA as a platform for post-translational modifications in the DNA damage
}

\section{response}

\author{
Alexandre Maréchal ${ }^{1}$, Lee Zou ${ }^{1,2}$ \\ ${ }^{1}$ Massachusetts General Hospital Cancer Center, Harvard Medical School, Charlestown, MA 02129, USA; ${ }^{2}$ Department of Pathol- \\ ogy, Massachusetts General Hospital, Harvard Medical School, Boston, MA 02114, USA
}

The Replication Protein A (RPA) complex is an essential regulator of eukaryotic DNA metabolism. RPA avidly binds to single-stranded DNA (sSDNA) through multiple oligonucleotide/oligosaccharide-binding folds and coordinates the recruitment and exchange of genome maintenance factors to regulate DNA replication, recombination and repair. The RPA-sSDNA platform also constitutes a key physiological signal which activates the master ATR kinase to protect and repair stalled or collapsed replication forks during replication stress. In recent years, the RPA complex has emerged as a key target and an important regulator of post-translational modifications in response to DNA damage, which is critical for its genome guardian functions. Phosphorylation and SUMOylation of the RPA complex, and more recently RPA-regulated ubiquitination, have all been shown to control specific aspects of DNA damage signaling and repair by modulating the interactions between RPA and its partners. Here, we review our current understanding of the critical functions of the RPA-sSDNA platform in the maintenance of genome stability and its regulation through an elaborate network of covalent modifications.

Keywords: RPA; post-translational modification; phosphorylation; ubiquitination; SUMOylation

Cell Research (2015) 25:9-23. doi:10.1038/cr.2014.147; published online 18 November 2014

\section{Introduction}

The single-stranded DNA (ssDNA)-binding protein complex Replication Protein A (RPA) plays crucial roles in virtually all aspects of eukaryotic DNA metabolism. Originally identified as an essential factor for the in vitro replication of simian virus 40 (SV40) DNA, it has since been recognized as a central regulator of the genome maintenance machinery [1-3]. Indeed, RPA is a bona fide genome guardian which functions during DNA replication, recombination and repair and also acts as a key sensor to elicit the DNA damage response (DDR) following cellular exposure to genotoxic stresses [4-7].

RPA participates in both the initiation and elongation steps of DNA replication by enhancing the assembly and recruitment of DNA polymerases $\alpha, \delta$, and $\varepsilon$, by pro-

Correspondence: Alexandre Maréchal ${ }^{\mathrm{a}}$, Lee Zou

${ }^{a}$ E-mail: amarechal@mgh.harvard.edu

${ }^{\mathrm{b}}$ E-mail: zou.lee@mgh.harvard.edu moting polymerase switch on the lagging strand and by coordinating the processing of Okazaki fragments [8-11]. Problems in DNA replication and other types of genotoxic stresses are signaled throughout the cell cycle via the detection of persistent stretches of RPA-ssDNA by the ATR kinase and its obligatory partner ATRIP [12]. ATR activation on RPA-ssDNA elicits cell cycle checkpoints, stabilizes stalled forks, promotes the repair of DNA damage and generally rewires the cell for the optimal maintenance of genome integrity $[13,14]$. RPA is also implicated in a number of DNA repair pathways, playing important roles during nucleotide excision repair (NER), base excision repair (BER), mismatch repair (MMR) and homologous recombination (HR) [15-17]. Furthermore, RPA has been suggested to function at telomeres in both yeast and human cells $[18,19]$.

The versatility of RPA bound to ssDNA (RPA-ssDNA) in DNA metabolism stems from the biochemical properties of this nucleoprotein structure, as well as its ability to orchestrate the recruitment, activation and exchange of a large number of proteins whose combined activi- 
ties permit the protection and propagation of eukaryotic genomes [5-7]. Although RPA interacts with multiple genome maintenance proteins to regulate DNA metabolism, the molecular mechanisms that allow RPA to participate in specific DNA metabolic pathways are not well understood. Post-translational modifications of the RPA complex particularly in response to DNA damage have emerged as critical regulators of the many functions of RPA-ssDNA. Here, we review recent advances in our understanding of the post-translational regulation of the RPA-ssDNA platform and its roles in the maintenance of genome stability.

\section{The ssDNA-binding domains of RPA}

RPA is a heterotrimeric complex composed of the RPA70, RPA32 and RPA14 subunits, which binds to ssDNA with very high affinity $\left(K_{\mathrm{d}} \sim 10^{-9}-10^{-10} \mathrm{M}\right)$ through multiple oligonucleotide/oligosaccharide-binding (OB) fold domains [20]. These domains, commonly referred to as DNA-binding domains (DBDs) A, B, C and $\mathrm{D}$, are located on the RPA70 (A, B, C) and RPA32 (D) subunits of the complex (Figure 1). RPA associates with ssDNA with a defined polarity $\left(5^{\prime} \rightarrow 3^{\prime}\right)$ using two different modes of binding. In the low-affinity binding mode, RPA uses only its DBD-A and -B to occlude 8 nucleotides (nts) of ssDNA [21, 22]. In its high-affinity binding mode, RPA uses DBD-A through -D to bind up to $30 \mathrm{nts}$ of ssDNA per RPA complex [23-30]. These two different binding modes appear to act sequentially to facilitate the initial association of RPA with ssDNA while also allowing its removal by DNA processing factors during DNA transactions [5]. Once bound to ssDNA, RPA protects it against breakage and acts as a platform that coordinates the arrival and departure of many genome maintenance factors [31]. There are at least three protein-protein interaction surfaces on the RPA complex which endow it with the flexibility required to direct multiple facets of DNA metabolism (Table 1).

\section{DBD-A and -B of RPA70}

In addition to their ssDNA-binding activity, DBD-A and $-\mathrm{B}$ can associate with other proteins. These pro-

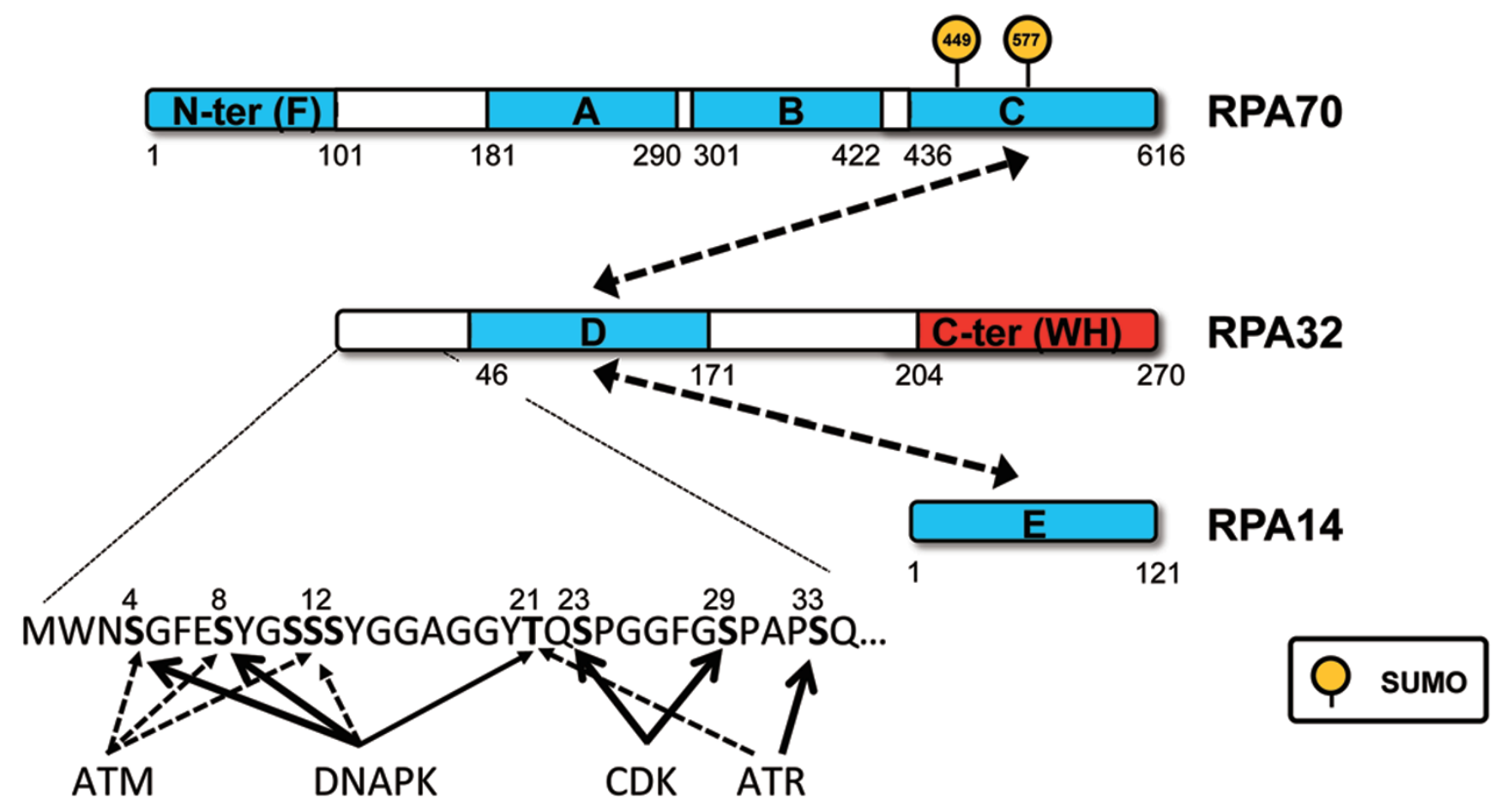

Figure 1 Schematic representation of the RPA complex. The OB folds A-F are shown as light blue rectangles, the winged-helix domain of RPA32 is in red. OB folds A-D (DBDs A-D) support the ssDNA-binding activity of the RPA complex. Heterotrimerization of the RPA complex is mediated by OB folds C of RPA70, D of RPA32 and E of RPA14, which are brought together through a triple helix bundle (dashed arrows) [23]. The phosphorylated residues found in the N-terminus of RPA32 are represented in bold along with their respective kinases. Solid and dashed arrows indicate major or minor contributions to specific phosphorylation events by the various kinases. SUMOylated residues in RPA70 are represented as orange circles. This figure was inspired by Fanning et al. [5]. 
Table 1 Known interactors of the RPA complex

\begin{tabular}{|c|c|c|}
\hline Protein Name & Interaction with RPA subunits & References \\
\hline AID & RPA32 & {$[152]$} \\
\hline ATR, ATRIP & RPA70 N & {$[12]$} \\
\hline BLM & RPA70 DBD-A/B & {$[153,154]$} \\
\hline BRCA2 & Unknown & {$[155]$} \\
\hline E1 papillomavirus protein & RPA70 & {$[33]$} \\
\hline EXO5 & RPA70 & {$[159]$} \\
\hline FACT (SPT16/SSRP1) & RPA70 & {$[160,161]$} \\
\hline FANCJ & RPA70 & {$[162]$} \\
\hline MRE11A, RAD50, NBS1 & RPA70 N & {$[34,164-166]$} \\
\hline NCL & RPA14 & {$[167]$} \\
\hline PP2A & Unknown & [122] \\
\hline PP4 (PP4C/PP4R2) & Unknown & {$[106]$} \\
\hline POL $\alpha$-primase & RPA70 & {$[168]$} \\
\hline POLD1/D2 & RPA70 & {$[11]$} \\
\hline PRP19 complex, PRP19/BCAS2 & RPA70 N, DBD-C & {$[49,138]$} \\
\hline p53 & RPA70 N & {$[37,169,170]$} \\
\hline PRIM-POL & RPA70 & {$[171]$} \\
\hline SMARCAL1/HARP & RPA70 DBD-A, RPA32 WH & {$[70-74]$} \\
\hline SV40 T antigen & RPA70 DBD-A and -B, RPA32 WH & {$[68,175,176]$} \\
\hline Tipin & RPA32 WH & {$[83,177]$} \\
\hline UNG2 & RPA32 WH & {$[178]$} \\
\hline WRN & RPA70 DBD-A/B & {$[179-181]$} \\
\hline XPA & RPA70 DBD-A, RPA32WH & {$[64,82,182-184]$} \\
\hline XPG & Unknown & {$[183,185,186]$} \\
\hline ERCC1-XPF & RPA70, RPA32 & {$[185-188]$} \\
\hline 53BP1 & Unknown & [118] \\
\hline
\end{tabular}

tein-protein interactions are regulated by the different DNA-binding modes of RPA [32]. For example, the SV40 T-antigen (TAg), a DNA helicase, interacts with RPA residues that are accessible when RPA is bound to DNA in the 8-nt binding mode but masked by ssDNA in the 30-nt binding mode. Additionally, conformational changes on DBD-A and -B during the transition from 8- to 30-nt binding mode also affect the binding surface of TAg and other factors on RPA [25, 32, 33]. These observations suggest a model in which the TAg first unwinds a short stretch of DNA at the replication origin and actively loads RPA in its 8-nt binding mode. The loading of RPA would then increase the unwinding activity of TAg and promote the transition into the 30-nt binding mode, 
leading to the subsequent dissociation of the TAg-RPA complex [32].

This type of "handoff" mechanism constitutes an important way of regulating the interactions of RPA with its partners. The handoff mechanism on RPA-ssDNA was also elegantly shown to promote the switch from DNA polymerase $\alpha$-primase to Pol $\delta$ during eukaryotic DNA replication [11]. Successive competition between different DNA processing proteins and ssDNA for the same binding surfaces on RPA can allow these factors to carry out specific functions as ssDNA is extended. Additionally, binding of proteins to different parts of the RPA complex may trigger conformational changes that would favor its further recognition by other factors and thus drive the completion of genome maintenance pathways [5]. Consistent with these possibilities, we and others have recently shown that ATR is activated by RPA-ssDNA in distinct ways toward Chk1 and RPA32 [34, 35]. In response to camptothecin (CPT) treatment, Chk1 and RPA32 are phosphorylated by ATR sequentially. Furthermore, CtIP, a protein critical for DNA end resection in human cells, is important for RPA32 phosphorylation but only plays a minor role in Chk1 phosphorylation [34-36]. These results suggest that different amounts of RPA-ssDNA are required for activating ATR toward Chk1 and RPA32. It is tempting to speculate that the handoff mechanism may allow RPA-ssDNA to coordinate checkpoint activation and DNA repair at sites of DNA damage, and regulate distinct DNA repair events spatially and temporally.

\section{The N-terminal OB fold of RPA70}

In contrast to DBDs A-C, the DBD-F located at the N-terminus of RPA70 does not significantly participate in the ssDNA-binding activity of the RPA complex but instead constitutes a key protein-protein interaction hub with crucial roles in DNA damage signaling [37-41]. The particular importance of this region for DDR activation is underscored by the Saccharomyces cerevisiae t-11 mutant, which is proficient for DNA replication but defective in DNA repair and checkpoint activation [42-45]. The t-11 mutant harbors a K-to-E mutation on the basic surface of the RPA70 N-terminus, which impairs its ability to interact with Ddc2/ATRIP and Ddc1/RAD9 and recruit them to damage sites [12, 46-48]. Analogous mutations on the human RPA70 N-terminus also lead to a defective G2/M checkpoint and abrogate its interaction with multiple partners many of which participate in ATR kinase activation including ATRIP, RAD9, the MRN (Mre11Rad50-Nbs1) complex, BID and the PRP19 complex [34, 41, 49-52].
The RPA70 N-terminus is thus a cornerstone of the DDR and functions as a checkpoint activation module in multiple ways. First, it recruits the ATR-ATRIP kinase complex to damage sites. Second, it facilitates the Rad17/ RFC-mediated loading of the Rad9-Hus1-Rad1 (9-1-1) checkpoint clamp onto ssDNA-dsDNA junctions, which promotes the interaction of 9-1-1 with the ATR activator TopBP1 [53-61]. Third, it brings in the MRN complex, which also interacts with TopBP1 and ATR-ATRIP [34, $41,62,63]$. And fourth, it nucleates additional factors such as the E3 ubiquitin ligase PRP19 to potentiate ATR activation on RPA-ssDNA (see Figure 2 and below).

\section{The winged helix domain of RPA32}

The winged helix (WH) domain at the RPA32 C-terminus also interacts with many genome maintenance proteins [64] (Table 1). In agreement with a function of this domain in genome protection, yeast truncation mutants lacking the C-terminal domain of Rfa2 (hRPA32) are hypersensitive to DNA damaging agents and exhibit mutator and hyper-recombination phenotypes [65, 66]. The RPA32 C-terminus also functions in SV40 DNA replication at least partly through its direct interaction with the TAg [67, 68].

RAD52, TIPIN, XPA, UNG2 and SMARCAL1 all interact with the RPA32 WH domain through similar short RPA-interacting peptides. The RPA32 WH is thus potentially involved in multiple DDR pathways as UNG2 functions in BER, XPA in NER, Rad52 in HR, and TIPIN and SMARCAL1 are both involved in replication fork protection and restart [69-79]. These interactions are all functionally meaningful as abrogation of the RPA-interacting domain on Rad52 rendered it unable to enhance HR when overexpressed in monkey cells, and truncation of the WH domain of RPA32 or deletion of the RPA-binding motif of XPA strongly impeded NER [80-82]. Additionally, SMARCAL1 mutants that cannot bind RPA are deficient in their genome maintenance functions [69-71]. Finally, a TIPIN RPA-binding motif mutant cannot support efficient CHK1 phosphorylation during replication stress [83].

Since all the protein-protein interaction domains of RPA have multiple partners which function in many very different processes, the assembly and disassembly of genome maintenance factors on RPA-ssDNA is unlikely to be solely controlled by the competition among RPA-binding proteins. Rather, the protein interactions of RPA-ssDNA are regulated by additional context-specific mechanisms. Among these mechanisms, post-translational modifications of the RPA complex may direct the specific functions of RPA-ssDNA in different sub-pathways of the DDR. 


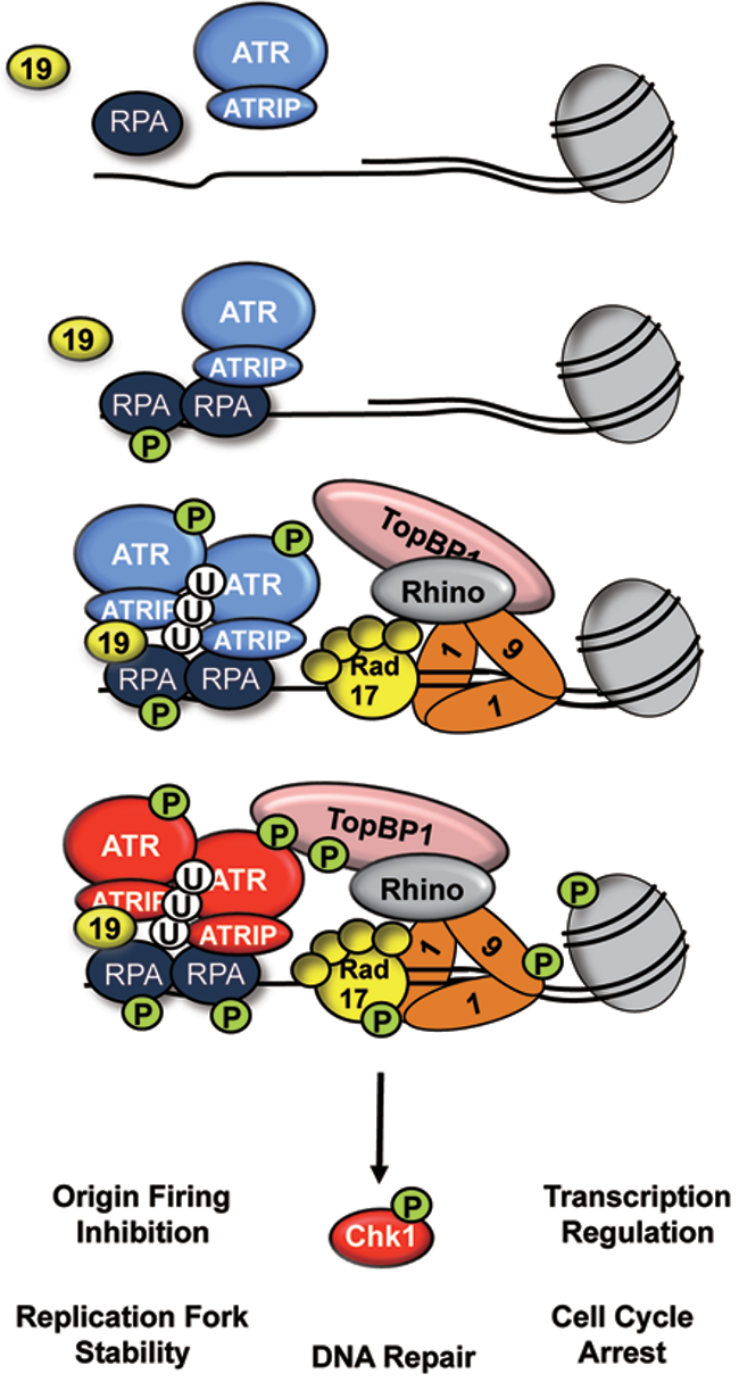

Figure 2 DNA damage signaling on RPA-ssDNA. RPA-ssDNA elicits DNA damage signaling by recruiting the ATR-ATRIP kinase and the PRP19 complex to trigger a phosphorylation-ubiquitination feed-forward loop that activates ATR-ATRIP. The kinase activity of ATR is required for efficient recruitment of the PRP19 complex onto RPA-ssDNA. PRP19 then exerts its ubiquitin ligase activity on the RPA-ssDNA platform to facilitate further recruitment of ATR-ATRIP and autophosphorylation of ATR. In parallel, RPA-ssDNA directs the loading of the 9-1-1 clamp by the Rad17-RFC2-5 complex onto adjacent ssDNA-dsDNA junctions. This allows the recruitment of the ATR activator TopBP1 and of Rhino, which potentiate ATR-ATRIP kinase activity to protect replication forks and maintain genomic stability. Phosphorylation and ubiquitination events are depicted as green and white circles, respectively.

\section{Phosphorylation of the RPA complex}

The most studied post-translational modification of the RPA complex is the phosphorylation of the RPA32 N-ter- minus first described more than 20 years ago [84]. RPA32 becomes phosphorylated at the G1/S phase transition and is subsequently dephosphorylated after mitosis during an unperturbed cell cycle $[84,85]$. These cell cycle-regulated phosphorylation events occur on consensus S/T-P CDK sites at serine residues S23 and S29 (Figure 1). Recently, phospho-specific antibodies were used to determine that phosphorylation occurs on S23 during S-phase, whereas both S23 and S29 are phosphorylated in mitosis [86]. It has also been established that cyclin A-Cdk2 phosphorylates RPA during S-phase while cyclin B-Cdk1 acts on RPA during mitosis [87-89].

In addition to these cell cycle-regulated phosphorylation events, the N-terminal part of RPA32 is phosphorylated at a number of other residues in response to DNA damage (Figure 1) [90-92]. In vitro SV40 DNA replication or the addition of ssDNA to S-100 extracts from HeLa cells can induce robust RPA phosphorylation, suggesting that ssDNA binding by the RPA complex is a prerequisite for its modification [93]. In agreement with this, DNA damaging agents that stall or break replication forks and thus rapidly generate high levels of RPA-ssDNA (e.g., ultraviolet light (UV), hydroxyurea (HU), CPT) strongly induce RPA32 hyperphosphorylation (phosphorylation at five or more sites), whereas agents that induce double-stranded breaks (DSBs) throughout the cell cycle such as ionizing radiation (IR) or bleomycin induce this modification modestly [94].

DNA damage-induced RPA hyperphosphorylation depends on the activity of the three DDR kinases of the phosphoinositide 3-kinase (PI3K)-like protein kinase (PIKK) family: ATM, ATR and DNA-PK (Figure 1). Crosstalk between these various kinases during RPA phosphorylation is complex and depends on the particular type of stress that is imposed on the cells [7, 95]. It was suggested that the phosphorylation of RPA32 at S33 is largely, if not exclusively, an ATR-specific event, whereas the phosphorylation at S4/S8 is mainly mediated by DNA-PK [34, 94, 96-99]. In response to CPT-induced replication-associated DSBs, RPA32 is sequentially phosphorylated by ATR at S33 and DNA-PKs at S4/S8 [34]. In the absence of ATR activity, HU induces gradual accumulation of ssDNA and eventually depletion of nuclear pools of RPA, and thus replication catastrophe [31]. During replication catastrophe, RPA32 is phosphorylated at T21 and S4/S8.

Priming phosphorylation events that promote further modification of adjacent residues are common in signaling pathways [100]. There is evidence for such interdependency between phosphorylation sites on RPA32. Cell cycle-dependent phosphorylation of RPA32 is required for efficient damage-induced phosphorylation. Indeed, 
high doses of ionizing radiation can induce RPA hyperphosphorylation, but it is reduced by mutations of the CDK-targeted S23 and S29 to alanines (S23/29A) [90]. CPT-induced hyperphosphorylation was also strongly impaired in RPA32 S23/29A or in cells exposed to the CDK inhibitor roscovitine [101]. Additional support for sequential RPA phosphorylation in response to damage comes from the fact that phosphorylation at residues T21 and S4/S8 is detected only in the hyperphosphorylated form of RPA, suggesting that these events occur after earlier priming phosphorylation at S29 and S33 [101]. Crosstalk is also a prominent feature between PIKK-targeted sites [97, 98]. Somewhat unexpectedly, phosphorylation of the consensus CDK target sites on RPA32 is induced following DNA damage [91]. Interestingly, mutation of T21 and S33 residues strongly reduced CPT-induced phosphorylation of S29 [101]. This suggests a model whereby CDK-dependent phosphorylation of RPA32 promotes damage-induced phosphorylation by PIKKs, which feeds back onto CDK phosphorylation sites ultimately promoting robust RPA hyperphosphorylation.

\section{RPA phosphorylation and DNA replication}

The role for RPA phosphorylation in DNA replication has been investigated by a number of studies. Truncation of the N-terminal part of RPA32 did not impede SV-40 DNA replication in vitro [67]. Additionally, no growth defects were observed in cell lines expressing RPA32 Ala7, a mutant in which seven RPA32 phosphorylation sites (S4/8/11/12/13/33A/T21A) are mutated to alanines, drastically reducing the levels of UV- and HU-induced RPA phosphorylation [96]. However, cells expressing an RPA32 mutant lacking S23 and S29 accumulated in S and G2 in the absence of exogenous stress, suggesting a role for CDK-mediated phosphorylation of RPA during normal cell cycle progression in vivo [101].

There is also evidence that hyperphosphorylation of RPA prevents its association with the replication machinery. For instance, UV light-induced RPA phosphorylation correlates with a decrease in DNA replication [92]. Moreover, endogenously phosphorylated RPA does not colocalize with sites of DNA synthesis and phosphomimetic RPA mutants associate poorly with replication factories [96, 102]. Nonetheless, phosphomimetic RPA mutants are still able to relocalize to damage-induced foci, suggesting that phosphorylation of RPA might be important to redirect its activities from DNA replication to DNA repair and genome protection [102]. Phosphorylation of RPA also appears to be important for the maintenance of telomere length. In yeast, an Rfa2 mutant lacking 40 amino acids at its $\mathrm{N}$-terminus had severely shortened telomeres. Mechanistically, the defect was caused by a decrease in the recruitment of the telomerase subunit Est1 to telomeres [18]. Whether RPA phosphorylation participates in telomere maintenance in mammalian cells is currently unknown. It should be noted that many of the previous studies on RPA phosphorylation used RPA32 mutants lacking some or all of the N-terminal phosphorylation sites. Proteomic studies have revealed that the RPA complex is phosphorylated at additional sites. Whether the phosphorylation events outside of the RPA32 N-terminus are functionally important remains to be tested.

\section{RPA phosphorylation and the DDR}

The role for RPA32 phosphorylation in DNA repair has also been investigated. An increase in the persistence and intensity of $\gamma-\mathrm{H} 2 \mathrm{AX}$ foci following CPT or bleomycin treatment was observed in cells expressing only the S23/29A mutant [101]. These mutant cells showed increased apoptosis when treated with CPT or bleomycin during mitosis. Furthermore, the S23/29A cells had less RAD51 chromatin loading after being treated with CPT or bleomycin in mitosis and released, suggesting that phosphorylation of RPA32 may regulate the formation of RAD51 filaments and the HR repair pathway [103]. Another mutant of RPA32, S33A/T21A had decreased DNA synthesis and increased accumulation of ssDNA after HU treatment. S33A/T21A also inhibited the recovery of DNA synthesis after genotoxic stress and was more sensitive to HU, indicating that RPA phosphorylation at stalled forks alleviates replication stress [97]. Using DNA fiber analysis, a recent study showed that the S23/29A and S33A/T21A mutants were defective in replication fork progression in the presence of $\mathrm{HU}$ and after HU release [104]. These two mutants were also defective in the proper nuclear localization of PALB2 and BRCA2 in HU-treated cells. Cells expressing an RPA32 mutant lacking seven phosphorylation sites (RPA32 Ala7: S4A, S8A, S11A, S12A, S13A, T21A and S33A) showed decreased RAD51 foci formation and HR after long HU treatment but not after IR [105], further implicating RPA phosphorylation in DNA repair. In contrast, cells expressing the S4/8A mutant had a slightly increased frequency of UV-induced sister chromatid exchange and modestly increased IR-induced RAD51 foci formation, suggesting that DNA-PK-dependent RPA phosphorylation is inhibitory to HR in these contexts [94]. Furthermore, phosphomimetic S8D and S33D mutations of RPA32 interfere with HR in the DR-GFP assay [106]. Together, these findings suggest that the phosphorylation of different sites of RPA32 may affect HR differently, and these 
effects may be context specific.

In addition to its role in DNA repair, RPA phosphorylation is also implicated in the checkpoint response. Cells expressing the S33A/T21A mutant are defective in ATR-dependent inhibition of DNA synthesis after UV irradiation, suggesting a role for RPA phosphorylation in the S-phase checkpoint [96]. Additional support for a role of RPA phosphorylation in checkpoint regulation comes from RPA phosphomimetic mutants containing S8/23/29/33D mutations, which showed stronger inhibition of DNA synthesis following $\gamma$-irradiation. These cells were also defective in RAD51 foci formation and HR repair and were more sensitive to CPT, suggesting that both phosphorylation and the timely dephosphorylation of RPA32 are required for genome stability [106]. Phosphorylation of S4/8 also contributes to G2/ $\mathrm{M}$ and S-phase checkpoint activation and the repair of etoposide-induced damage [94, 98]. For example, the S4/8A mutant is defective in Chk1, Mre11 and TopBP1 phosphorylation in response to etoposide [98]. Recently, it was shown that cells expressing the S4/8A mutant restart replication prematurely during the recovery from etoposide-induced DNA damage, indicating a defect in sustaining the proper checkpoint response [107]. Cells lacking DNA-PKcs or expressing a kinase-inactive DNA-PKcs mutant also had decreased Chk1 phosphorylation, thereby implicating DNA-PK in ATR activation. A role for DNA-PK in ATR activation was also recently demonstrated on short-gapped ssDNA in human cell-free extracts and proposed to stem from its ability to promote both RPA and TopBP1 phosphorylation [108]. However, the RPA32 Ala7 mutant did not display a defect in Chk1 phosphorylation after UV, HU or IR treatments, although cells expressing the mutant failed to inhibit DNA synthesis after UV damage [96]. It is possible that the role for RPA phosphorylation in ATR activation is context specific. Alternatively, the phosphorylation of RPA32 by different kinases may have opposing effects on ATR activation.

\section{RPA phosphorylation and protein-protein interac- tions}

Binding between phospho-recognition motifs such as the Forkhead associated (FHA) or BRCT (BRCA1 C-terminal) domains and phosphorylated proteins plays a crucial role in cell cycle regulation and DNA damage signaling and repair [109]. Phospho-dependent protein complex formation underlies the $\gamma-\mathrm{H} 2 \mathrm{AX}$ chromatin-based axis of the DDR and participates in the elaboration of multiple repair pathways $[110,111]$. Hyperphosphorylation of the RPA complex also modulates its interactions with other proteins and nucleic acids.

Phosphorylated RPA obtained by incubation of recombinant human RPA complexes with HeLa nuclear extracts has a decreased affinity for purine-rich ssDNA and undamaged dsDNA, but showed enhanced binding to cisplatin-damaged dsDNA compared with non-phosphorylated RPA [112]. Similarly, phospho-RPA purified from mitotic cells had intact ssDNA binding but decreased dsDNA binding [113]. Phosphomimetic RPA complex was also shown to have a decreased helix destabilization activity [114].

Phosphorylation of RPA32 can negatively impact its interactions with other proteins. Phospho-RPA has an impaired interaction with DNA polymerase $\alpha$ and a decreased ability to support SV40 DNA replication [113]. Mitosis-specific phosphorylated RPA has defective interactions with ATM, DNA-PK and DNA polymerase $\alpha$ but still binds to the NER factor XPA [113]. Phosphomimetic RPA also has a weakened interaction with the MRN complex possibly through a competition between MRN and the negatively charged phospho-RPA32 for the basic cleft of RPA70 N-terminus [41, 114]. Such competition was also reported between p53 and a phosphomimetic peptide of the RPA32 N-terminus [37]. In agreement with this, hyperphosphorylated RPA32 shows an abrogated interaction with p53 in an ATR-, ATM- and DNA-PK-regulated manner $[115,116]$. It has also been reported that $\mathrm{CPT}$ treatment leads to the dissociation of an RPA-DNA-PK complex concomitantly with RPA phosphorylation and a decrease in DNA synthesis [117]. Association between RPA and 53BP1 is also disrupted after CPT treatment, although the significance of this impaired interaction is unclear [118].

RPA phosphorylation can also positively regulate its interactions with other proteins. The RAD51 and RAD52 HR proteins were shown to associate preferentially with phosphorylated RPA both in vivo and in vitro [119]. Whether these interactions are directly mediated by phosphorylation of RPA is still unclear. The interaction between the MRN complex and RPA was also shown to be phosphatase sensitive, but the RPA-interacting motif of NBS1 lies outside of its BRCT and FHA domains, and the Mre11-RPA interaction is not mediated by a putative phospho-binding domain $[34,50,62,120]$. The ATR kinase and the 9-1-1 checkpoint clamp also exhibit a preference for phospho-RPA [119, 121]. Moreover, the PRP19 E3 ubiquitin ligase, which drives ATR-ATRIP recruitment and activation on RPA-ssDNA, interacts preferentially with hyperphosphorylated RPA. Indeed, the RPA-PRP19 interaction is facilitated by the ATR kinase, which results in a feed-forward amplification loop that potentiates ATR activation [49]. These data show 
that in concordance with roles for RPA phosphorylation in checkpoint activation and DNA repair, specific components of both the DDR signaling and HR repair pathways associate preferentially with phospho-RPA. A recent study suggested that the RPA complex phosphorylated by cyclin $\mathrm{B}-\mathrm{Cdc} 2$ in vitro promoted the binding of PALB2 to ssDNA in cell extracts [104]. However, despite all these tantalizing links, it is still unclear which of the many protein-protein interactions occurring on the RPA-ssDNA platform are directly mediated by RPA phosphorylation.

\section{Dephosphorylation of RPA}

The defects in DNA repair in cells expressing phosphomimetic RPA mutants suggest that RPA dephosphorylation is important to successfully preserve genome integrity. Two different phosphatases seem to regulate RPA dephosphorylation in response to DNA damage [106, 122]. Interference with the serine/threonine phosphatase PP2A caused persistent RPA32 phosphorylation and increased sensitivity to HU-induced replication stress. Consistent with the phosphomimetic RPA32 T21D/S33D mutant phenotypes, PP2A-knockdown cells were also impaired in the resolution of HU-induced fork damage but not defective in checkpoint activation [122]. Another serine/threonine phosphatase, PP4, interacts with the RPA complex via its regulatory subunit PP4R2 in a damage-dependent fashion to regulate the level of RPA phosphorylation [106]. PP4 limits the levels of RPA32 hyperphosphorylation, which occurs following CPT treatment. PP4C and PP4R2 downregulation also decreased HR efficiency as measured by the I-Sce-I DR-GFP assay and the repair of CPT-induced DSBs. Recombination and repair defects were also observed in cells expressing the phosphomimetic RPA32 S8/23/29/33D mutant. It is noteworthy that the dephosphorylation of RPA32 following HU treatment did not depend on PP4, and CPT-induced hyperphosphorylation was not increased by PP2A downregulation $[106,122]$. These results raise the possibility that different types of DNA damage may mobilize specific protein phosphatases to modulate the DDR on the RPA-ssDNA platform.

\section{SUMOylation of RPA}

Recent evidence shows that upon DNA damage both the yeast and human RPA complexes become SUMOylated [123-126]. In yeast, the SUMOylation of RPA was demonstrated by SUMO pull-down under denaturing conditions [124, 125]. In human cells, treatment with CPT causes a dissociation of the SENP6 deSUMOylase from RPA70, leading to accumulation of a modified form of RPA70 that was recognized by anti-SUMO-2/3 antibodies [123]. The modified amino acids on RPA70 were mapped to lysine residues 449 and 577 (Figure 1). Mechanistically, SUMOylation of DNA repair proteins appears to trigger the assembly of macromolecular complexes through SIM (SUMO-Interacting Motif)-SUMO interactions between the various components of the complexes [124]. RPA70 SUMOylation increased its interaction with RAD51 and enhanced the RAD51 ATPase activity. Replacement of endogenous RPA70 with non-SUMOylatable mutants showed that SUMOylation of this RPA subunit promotes RAD51 foci formation and DNA repair through HR. Additionally, cells expressing the K449R/ K577R RPA70 mutant had increased sensitivity to CPT, demonstrating the importance of RPA complex SUMOylation for the maintenance of genomic stability. Interestingly, recruitment of RAD51 to sites of damage was recently shown to require a SIM domain [127]. Additionally, the RPA complex may also have SUMO-recognition capacity. Yeast Rfa1 seems to contain at least two putative SIMs, one of which can bind poly-SUMO chains in vitro [124]. SUMOylation of proteins may also be achieved as part of hierarchical cascades of post-translational modifications that confer increased specificity to signaling pathways [128]. For example, SUMOylation has been shown to trigger recognition of substrates by SUMO-Targeted Ubiquitin Ligases (STUbLs) leading to the degradation of SUMOylated proteins and maintenance of the homeostasis of the SUMO pathway [129].

\section{Ubiquitination of the RPA complex}

All three subunits of the RPA complex are ubiquitinated following DNA damage $[49,130]$. We recently carried out a proteomic screen for sensors of RPA-ssDNA and identified the PRP19 E3 ubiquitin ligase complex as a direct interactor of the RPA complex in response to DNA damage [49]. The PRP19 complex is an important regulator of pre-mRNA splicing and also plays key roles in the DDR [131-136]. It is composed of PRP19, a U-box family ubiquitin ligase, and three other core components, CDC5L, BCAS2 and PLRG1 [137]. Both PRP19 and BCAS2 interact directly with the RPA complex and this interaction tethers the PRP19 complex to sites of damage [49, 138]. Functionally, PRP19 is required for optimal Chk1 and RPA32 phosphorylation in response to damage and promotes the repair of stalled and collapsed replication forks. The defects of PRP19-knockdown cells in Chk1 and RPA32 phosphorylation correlate with a decrease in the recruitment and activation of the ATRATRIP kinase on RPA-ssDNA. All of these phenotypes 
can be rescued by WT PRP19 but not by PRP19 mutants that cannot bind RPA or ubiquitinate substrates [49, 138]. These data indicate that during the DDR, PRP19 functions as a ubiquitin ligase on RPA-ssDNA. In support of this, overexpression of PRP19 led to enhanced damage-induced RPA32 ubiquitination, whereas PRP19 knockdown strongly decreased both exogenous and endogenous RPA32 mono- and polyubiquitination in damaged cells. In vitro, however, the PRP19 complex could only monoubiquitinate RPA32, raising the possibility that additional E2/E3 partners may be necessary to achieve polyubiquitination of RPA in vivo.

In response to damage, RPA32 is decorated by K63linked ubiquitin chains, which are known to promote protein-protein interactions. Since PRP19 facilitates checkpoint activation, we asked whether known RPA interactors involved in ATR activation also bind to ubiquitin chains. We found that ATRIP specifically interacts with K63-linked tetra-ubiquitin molecules but not with K48-linked chains. These observations allowed us to propose a model whereby the ubiquitination of RPA or other DDR proteins by PRP19 promotes the recruitment and activation of ATR-ATRIP at sites of damage (Figure 2). The ATR kinase itself is required for efficient RPAPRP19 interaction and RPA ubiquitination (unpublished data by Maréchal A and Zou L), suggesting the presence of a phosphorylation- and ubiquitination-mediated feed-forward loop that ensures the rapid and efficient activation of ATR in response to DNA damage and replication stress. Interestingly, PRP19 was also recently found to promote HR, implicating it in another facet of the DDR that takes place on RPA-ssDNA [139]. Thus, RPA-ssDNA is both the platform that recruits the PRP19 complex and a substrate of the E3 ligase. It is important to note that RPA may not be the only substrate of PRP19 at sites of DNA damage. In addition to RPA, other DDR proteins associated with RPA-ssDNA may also be ubiquitinated by the PRP19 complex. Although RPA is ubiquitinated in a PRP19-dependent manner, whether RPA is the key substrate of PRP19 in the DDR remains to be tested. Moreover, RPA-ssDNA may recruit additional ubiquitin ligases to sites of DNA damage [140-143]. Further studies are still needed to fully elucidate the ubiquitination circuitry on RPA-ssDNA and its functions.

\section{RNF4 and RPA}

RNF4 is a STUbL that regulates multiple aspects of the DDR [144-148]. Efficient recruitment of RNF4 to sites of DNA damage requires its tandem SIM domains, suggesting that it is tethered to damage foci by SUMOylated proteins [144, 147, 148]. Following its recruitment to DNA lesions, RNF4 ubiquitinates many different SUMOylated targets to regulate the DDR [149]. Two studies found that RNF4 controls DSB resection and HR-mediated DNA repair upstream of the formation of RPA-ssDNA by regulating the recruitment of CtIP to breaks $[145,148]$. Another study, however, suggested that RNF4 regulates HR at a post-resection step by promoting the ubiquitination and turnover of RPA [144]. Residence time of GFP-tagged RPA70 at damaged sites was increased in RNF4-deficient cells. The non-SUMOylatable RPA70 mutant K449/577R also had a longer residence time compared with WT and it was not further increased in RNF4-depleted cells. Cells expressing the K449/577R mutant of RPA70 displayed reduced recruitment of RAD51 and BRCA2 to laser-induced DSBs, confirming that RPA SUMOylation controls the later steps of the HR-mediated DNA repair pathway [123]. Finally, an increase in the interaction between RPA and the PSMD4 19S proteasomal component after IR was found to be RNF4 dependent [144]. However, the direct ubiquitination of SUMOylated RPA70 by RNF4 remains to be demonstrated. Regardless of whether RNF4 directly ubiquitinates RPA70, it links the ubiquitination and SUMOylation at sites of DNA damage and plays an important role in RPA regulation during the DDR.

\section{Concluding remarks}

Numerous publications in recent years have eloquently shown that phosphorylation, SUMOylation and ubiquitination events are rapidly induced on the chromatin surrounding DSBs. This complex modification of the chromatin is carried out by a plethora of writers including PI3K-like kinases as well as many different SUMO and E3 ubiquitin ligases. The decoration of chromatin-associated DDR factors provides the required specificity to tether additional effectors to sites of damage. These factors often behave as readers that bind to the altered surfaces through exquisitely specific interaction motifs, which recognize both the modified proteins themselves and their modifications $[150,151]$. This high degree of specificity allows the elaborate modification of the $\gamma$-H2AX DDR platform to govern the DSB repair pathway choice by modulating the chromatin association of 53BP1 which promotes non-homologous end joining and of BRCA1, a crucial HR regulator [149].

Similarly, the RPA-ssDNA platform is extensively phosphorylated, SUMOylated and ubiquitinated in response to damage. These post-translational alterations of RPA regulate the activation of the ATR checkpoint and also promote DNA repair, particularly through the HR pathway. However, our molecular understanding of 
events occurring on RPA-ssDNA has lagged behind that of the chromatin-centered DDR. A deeper understanding of the writers and readers that function on both chromatin and RPA-ssDNA to coordinate the assembly and disassembly of signaling and repair factors will lead to a much more complete picture of the DDR and could uncover novel targets to enhance the efficiency of current chemotherapeutic regimens. In particular, the identification of domains that allow DDR factors to specifically interact with modified RPA, the characterization of the full extent of damage-induced RPA modifications and the discovery of the writers responsible for these alterations should all be actively pursued. Research on RPA has been a very fruitful area for almost 30 years and the ongoing elucidation of the choreography of events that occur on both RPA-ssDNA and chromatin in response to DNA damage will provide us with exciting new insights on the elegant strategies used by our cells to preserve genome integrity.

\section{Acknowledgments}

We apologize to all of our colleagues whose work we could not cite due to space restrictions. We want to thank Rémi Buisson, Jian Ouyang, Hai Dang Nguyen and Stephanie A Yazinski for critical reading of the manuscript and all members of the Zou Lab for fruitful discussions. This work is supported by the NIH grant GM076388 and the federal share of proton program to LZ.

\section{References}

1 Wobbe CR, Weissbach L, Borowiec JA, et al. Replication of simian virus 40 origin-containing DNA in vitro with purified proteins. Proc Natl Acad Sci USA 1987; 84:1834-1838.

2 Wold MS, Kelly T. Purification and characterization of replication protein $\mathrm{A}$, a cellular protein required for in vitro replication of simian virus 40 DNA. Proc Natl Acad Sci USA 1988; 85:2523-2527.

3 Fairman MP, Stillman B. Cellular factors required for multiple stages of SV40 DNA replication in vitro. EMBO J 1988; 7:1211-1218.

4 Flynn RL, Zou L. Oligonucleotide/oligosaccharide-binding fold proteins: a growing family of genome guardians. Crit Rev Biochem Mol Biol 2010; 45:266-275.

5 Fanning E, Klimovich V, Nager AR. A dynamic model for replication protein A (RPA) function in DNA processing pathways. Nucleic Acids Res 2006; 34:4126-4137.

6 Wold MS. Replication protein A: a heterotrimeric, single-stranded DNA-binding protein required for eukaryotic DNA metabolism. Annu Rev Biochem 1997; 66:61-92.

7 Oakley GG, Patrick SM. Replication protein A: directing traffic at the intersection of replication and repair. Front Biosci (Landmark Ed) 2010; 15:883-900.

8 Bae SH, Bae KH, Kim JA, Seo YS. RPA governs endonuclease switching during processing of Okazaki fragments in eukaryotes. Nature 2001; 412:456-461.

9 Dornreiter I, Erdile LF, Gilbert IU, von Winkler D, Kelly
TJ, Fanning E. Interaction of DNA polymerase alpha-primase with cellular replication protein A and SV40 T antigen. EMBO J 1992; 11:769-776.

10 Waga S, Stillman B. Anatomy of a DNA replication fork revealed by reconstitution of SV40 DNA replication in vitro. Nature 1994; 369:207-212.

11 Yuzhakov A, Kelman Z, Hurwitz J, O’Donnell M. Multiple competition reactions for RPA order the assembly of the DNA polymerase delta holoenzyme. EMBO J 1999; 18:61896199.

12 Zou L, Elledge SJ. Sensing DNA damage through ATRIP recognition of RPA-ssDNA complexes. Science 2003; 300:1542-1548.

13 Maréchal A, Zou L. DNA damage sensing by the ATM and ATR kinases. Cold Spring Harb Perspect Biol 2013; 5. pii: a012716.

14 Cimprich KA, Cortez D. ATR: an essential regulator of genome integrity. Nat Rev Mol Cell Biol 2008; 9:616-627.

15 Li GM. Mechanisms and functions of DNA mismatch repair. Cell Res 2008; 18:85-98.

16 Krejci L, Altmannova V, Spirek M, Zhao X. Homologous recombination and its regulation. Nucleic Acids Res 2012; 40:5795-5818.

17 Iyama T, Wilson DM 3rd. DNA repair mechanisms in dividing and non-dividing cells. DNA Repair (Amst) 2013; 12:620-636

18 Schramke V, Luciano P, Brevet V, et al. RPA regulates telomerase action by providing Est1p access to chromosome ends. Nat Genet 2004; 36:46-54.

19 Grudic A, Jul-Larsen A, Haring SJ, et al. Replication protein A prevents accumulation of single-stranded telomeric DNA in cells that use alternative lengthening of telomeres. Nucleic Acids Res 2007; 35:7267-7278.

20 Kim C, Paulus BF, Wold MS. Interactions of human replication protein A with oligonucleotides. Biochemistry 1994; 33:14197-14206.

21 Arunkumar AI, Stauffer ME, Bochkareva E, Bochkarev A, Chazin WJ. Independent and coordinated functions of replication protein A tandem high affinity single-stranded DNA binding domains. J Biol Chem 2003; 278:41077-41082.

22 Bochkarev A, Pfuetzner RA, Edwards AM, Frappier L. Structure of the single-stranded-DNA-binding domain of replication protein A bound to DNA. Nature 1997; 385:176181.

23 Bochkareva E, Korolev S, Lees-Miller SP, Bochkarev A. Structure of the RPA trimerization core and its role in the multistep DNA-binding mechanism of RPA. EMBO J 2002; 21:1855-1863.

24 Bochkareva E, Belegu V, Korolev S, Bochkarev A. Structure of the major single-stranded DNA-binding domain of replication protein A suggests a dynamic mechanism for DNA binding. EMBO J 2001; 20:612-618.

25 Fan J, Pavletich NP. Structure and conformational change of a replication protein A heterotrimer bound to ssDNA. Genes Dev 2012; 26:2337-2347.

26 Wyka IM, Dhar K, Binz SK, Wold MS. Replication protein A interactions with DNA: differential binding of the core domains and analysis of the DNA interaction surface. Biochemistry 2003; 42:12909-12918. 
27 Blackwell LJ, Borowiec JA. Human replication protein A binds single-stranded DNA in two distinct complexes. Mol Cell Biol 1994; 14:3993-4001.

28 Lao Y, Lee CG, Wold MS. Replication protein A interactions with DNA. 2. Characterization of double-stranded DNA-binding/helix-destabilization activities and the role of the zinc-finger domain in DNA interactions. Biochemistry 1999; 38:3974-3984.

29 Brill SJ, Bastin-Shanower S. Identification and characterization of the fourth single-stranded-DNA binding domain of replication protein A. Mol Cell Biol 1998; 18:7225-7234.

30 Bastin-Shanower SA, Brill SJ. Functional analysis of the four DNA binding domains of replication protein A. The role of RPA2 in ssDNA binding. $J$ Biol Chem 2001; 276:3644636453.

31 Toledo LI, Altmeyer M, Rask MB, et al. ATR prohibits replication catastrophe by preventing global exhaustion of RPA. Cell 2013; 155:1088-1103.

32 Jiang X, Klimovich V, Arunkumar AI, et al. Structural mechanism of RPA loading on DNA during activation of a simple pre-replication complex. EMBO J 2006; 25:5516-5526.

33 Loo YM, Melendy T. Recruitment of replication protein A by the papillomavirus E1 protein and modulation by single-stranded DNA. J Virol 2004; 78:1605-1615.

34 Shiotani B, Nguyen HD, Hakansson P, et al. Two distinct modes of ATR activation orchestrated by Rad17 and Nbs1. Cell Rep 2013; 3:1651-1662.

35 Kousholt AN, Fugger K, Hoffmann S, et al. CtIP-dependent DNA resection is required for DNA damage checkpoint maintenance but not initiation. J Cell Biol 2012; 197:869876.

36 Sartori AA, Lukas C, Coates J, et al. Human CtIP promotes DNA end resection. Nature 2007; 450:509-514.

37 Bochkareva E, Kaustov L, Ayed A, et al. Single-stranded DNA mimicry in the p53 transactivation domain interaction with replication protein A. Proc Natl Acad Sci USA 2005; 102:15412-15417.

38 Jacobs DM, Lipton AS, Isern NG, et al. Human replication protein A: global fold of the N-terminal RPA-70 domain reveals a basic cleft and flexible C-terminal linker. J Biomol NMR 1999; 14:321-331.

39 Binz SK, Wold MS. Regulatory functions of the N-terminal domain of the 70-kDa subunit of replication protein A (RPA). J Biol Chem 2008; 283:21559-21570.

40 Gomes XV, Henricksen LA, Wold MS. Proteolytic mapping of human replication protein A: evidence for multiple structural domains and a conformational change upon interaction with single-stranded DNA. Biochemistry 1996; 35:55865595.

41 Oakley GG, Tillison K, Opiyo SA, Glanzer JG, Horn JM, Patrick SM. Physical interaction between replication protein A (RPA) and MRN: involvement of RPA2 phosphorylation and the N-terminus of RPA1. Biochemistry 2009; 48:74737481.

42 Umezu K, Sugawara N, Chen C, Haber JE, Kolodner RD. Genetic analysis of yeast RPA1 reveals its multiple functions in DNA metabolism. Genetics 1998; 148:989-1005.

43 Kim HS, Brill SJ. Rfc4 interacts with Rpa1 and is required for both DNA replication and DNA damage checkpoints in
Saccharomyces cerevisiae. Mol Cell Biol 2001; 21:37253737.

44 Pellicioli A, Lee SE, Lucca C, Foiani M, Haber JE. Regulation of Saccharomyces Rad53 checkpoint kinase during adaptation from DNA damage-induced G2/M arrest. Mol Cell 2001; 7:293-300.

45 Lee SE, Moore JK, Holmes A, Umezu K, Kolodner RD, Haber JE. Saccharomyces Ku70, mre11/rad50 and RPA proteins regulate adaptation to $\mathrm{G} 2 / \mathrm{M}$ arrest after DNA damage. Cell 1998; 94:399-409.

46 Zou L, Liu D, Elledge SJ. Replication protein A-mediated recruitment and activation of Rad17 complexes. Proc Natl Acad Sci USA 2003; 100:13827-13832.

47 Lucca C, Vanoli F, Cotta-Ramusino C, et al. Checkpoint-mediated control of replisome-fork association and signalling in response to replication pausing. Oncogene 2004; 23:12061213.

48 Majka J, Binz SK, Wold MS, Burgers PM. Replication protein A directs loading of the DNA damage checkpoint clamp to 5'-DNA junctions. J Biol Chem 2006; 281:27855-27861.

49 Maréchal A, Li JM, Ji XY, et al. PRP19 transforms into a sensor of RPA-ssDNA after DNA damage and drives ATR activation via a ubiquitin-mediated circuitry. Mol Cell 2014; 53:235-246.

$50 \mathrm{Xu}$ X, Vaithiyalingam S, Glick GG, Mordes DA, Chazin WJ, Cortez D. The basic cleft of RPA70N binds multiple checkpoint proteins, including RAD9, to regulate ATR signaling. Mol Cell Biol 2008; 28:7345-7353.

51 Haring SJ, Mason AC, Binz SK, Wold MS. Cellular functions of human RPA1. Multiple roles of domains in replication, repair, and checkpoints. J Biol Chem 2008; 283:1909519111.

52 Liu Y, Vaithiyalingam S, Shi Q, Chazin WJ, Zinkel SS. BID binds to replication protein A and stimulates ATR function following replicative stress. Mol Cell Biol 2011; 31:42984309.

53 Kumagai A, Lee J, Yoo HY, Dunphy WG. TopBP1 activates the ATR-ATRIP complex. Cell 2006; 124:943-955.

54 Mordes DA, Glick GG, Zhao R, Cortez D. TopBP1 activates ATR through ATRIP and a PIKK regulatory domain. Genes Dev 2008; 22:1478-1489.

55 Lee J, Dunphy WG. Rad17 plays a central role in establishment of the interaction between TopBP1 and the Rad9-Hus1Rad1 complex at stalled replication forks. Mol Biol Cell 2010; 21:926-935.

56 Lee J, Kumagai A, Dunphy WG. The Rad9-Hus1-Rad1 checkpoint clamp regulates interaction of TopBP1 with ATR. J Biol Chem 2007; 282:28036-28044.

57 Delacroix S, Wagner JM, Kobayashi M, Yamamoto K, Karnitz LM. The Rad9-Hus1-Rad1 (9-1-1) clamp activates checkpoint signaling via TopBP1. Genes Dev 2007; 21:14721477.

58 Puddu F, Granata M, Di Nola L, et al. Phosphorylation of the budding yeast 9-1-1 complex is required for Dpb11 function in the full activation of the UV-induced DNA damage checkpoint. Mol Cell Biol 2008; 28:4782-4793.

59 Mordes DA, Nam EA, Cortez D. Dpb11 activates the Mec1Ddc2 complex. Proc Natl Acad Sci USA 2008; 105:1873018734. 
60 Navadgi-Patil VM, Burgers PM. Yeast DNA replication protein Dpb11 activates the Mec1/ATR checkpoint kinase. $J$ Biol Chem 2008; 283:35853-35859.

61 Liu S, Shiotani B, Lahiri M, et al. ATR autophosphorylation as a molecular switch for checkpoint activation. Mol Cell 2011; 43:192-202.

62 Olson E, Nievera CJ, Liu E, Lee AY, Chen L, Wu X. The Mre11 complex mediates the S-phase checkpoint through an interaction with replication protein A. Mol Cell Biol 2007; 27:6053-6067.

63 Yoo HY, Kumagai A, Shevchenko A, Dunphy WG. The Mre11-Rad50-Nbs1 complex mediates activation of TopBP1 by ATM. Mol Biol Cell 2009; 20:2351-2360.

64 Mer G, Bochkarev A, Gupta R, et al. Structural basis for the recognition of DNA repair proteins UNG2, XPA, and RAD52 by replication factor RPA. Cell 2000; 103:449-456.

65 Santocanale C, Neecke H, Longhese MP, Lucchini G, Plevani P. Mutations in the gene encoding the $34 \mathrm{kDa}$ subunit of yeast replication protein A cause defective $\mathrm{S}$ phase progression. J Mol Biol 1995; 254:595-607.

66 Maniar HS, Wilson R, Brill SJ. Roles of replication protein-A subunits 2 and 3 in DNA replication fork movement in Saccharomyces cerevisiae. Genetics 1997; 145:891-902.

67 Lee SH, Kim DK. The role of the 34-kDa subunit of human replication protein A in simian virus 40 DNA replication in vitro. J Biol Chem 1995; 270:12801-12807.

68 Arunkumar AI, Klimovich V, Jiang X, et al. Insights into hRPA32 C-terminal domain-mediated assembly of the simian virus 40 replisome. Nat Struct Mol Biol 2005; 12:332-339.

69 Ciccia A, Bredemeyer AL, Sowa ME, et al. The SIOD disorder protein SMARCAL1 is an RPA-interacting protein involved in replication fork restart. Genes Dev 2009; 23:24152425.

70 Bansbach CE, Betous R, Lovejoy CA, Glick GG, Cortez D. The annealing helicase SMARCAL1 maintains genome integrity at stalled replication forks. Genes Dev 2009; 23:24052414.

71 Yuan J, Ghosal G, Chen J. The annealing helicase HARP protects stalled replication forks. Genes Dev 2009; 23:23942399.

72 Postow L, Woo EM, Chait BT, Funabiki H. Identification of SMARCAL1 as a component of the DNA damage response. $J$ Biol Chem 2009; 284:35951-35961.

73 Couch FB, Bansbach CE, Driscoll R, et al. ATR phosphorylates SMARCAL1 to prevent replication fork collapse. Genes Dev 2013; 27:1610-1623.

74 Yusufzai T, Kong X, Yokomori K, Kadonaga JT. The annealing helicase HARP is recruited to DNA repair sites via an interaction with RPA. Genes Dev 2009; 23:2400-2404.

75 Leman AR, Noguchi E. Local and global functions of Timeless and Tipin in replication fork protection. Cell Cycle 2012; 11:3945-3955.

76 Lok BH, Powell SN. Molecular pathways: understanding the role of Rad52 in homologous recombination for therapeutic advancement. Clin Cancer Res 2012; 18:6400-6406.

77 Diderich K, Alanazi M, Hoeijmakers JH. Premature aging and cancer in nucleotide excision repair-disorders. DNA Repair (Amst) 2011; 10:772-780.

78 Krokan HE, Bjoras M. Base excision repair. Cold Spring
Harb Perspect Biol 2013; 5:a012583.

79 Errico A, Costanzo V, Hunt T. Tipin is required for stalled replication forks to resume DNA replication after removal of aphidicolin in Xenopus egg extracts. Proc Natl Acad Sci USA 2007; 104:14929-14934.

80 Park MS, Ludwig DL, Stigger E, Lee SH. Physical interaction between human RAD52 and RPA is required for homologous recombination in mammalian cells. J Biol Chem 1996; 271:18996-19000.

81 Stigger E, Drissi R, Lee SH. Functional analysis of human replication protein A in nucleotide excision repair. $J$ Biol Chem 1998; 273:9337-9343.

82 Li L, Lu X, Peterson CA, Legerski RJ. An interaction between the DNA repair factor XPA and replication protein A appears essential for nucleotide excision repair. $\mathrm{Mol}$ Cell Biol 1995; 15:5396-5402.

83 Kemp MG, Akan Z, Yilmaz S, et al. Tipin-replication protein A interaction mediates Chk1 phosphorylation by ATR in response to genotoxic stress. J Biol Chem 2010; 285:1656216571.

84 Din S, Brill SJ, Fairman MP, Stillman B. Cell-cycle-regulated phosphorylation of DNA replication factor A from human and yeast cells. Genes Dev 1990; 4:968-977.

85 Brill SJ, Stillman B. Yeast replication factor-A functions in the unwinding of the SV40 origin of DNA replication. $\mathrm{Na}$ ture 1989; 342:92-95.

86 Stephan H, Concannon C, Kremmer E, Carty MP, Nasheuer HP. Ionizing radiation-dependent and independent phosphorylation of the $32-\mathrm{kDa}$ subunit of replication protein A during mitosis. Nucleic Acids Res 2009; 37:6028-6041.

87 Dutta A, Stillman B. cdc2 family kinases phosphorylate a human cell DNA replication factor, RPA, and activate DNA replication. EMBO J 1992; 11:2189-2199.

88 Fang F, Newport JW. Distinct roles of cdk2 and cdc2 in RP-A phosphorylation during the cell cycle. J Cell Sci 1993; 106:983-994.

89 Pan ZQ, Amin AA, Gibbs E, Niu H, Hurwitz J. Phosphorylation of the p34 subunit of human single-stranded-DNA-binding protein in cyclin A-activated G1 extracts is catalyzed by cdk-cyclin A complex and DNA-dependent protein kinase. Proc Natl Acad Sci USA 1994; 91:8343-8347.

90 Liu VF, Weaver DT. The ionizing radiation-induced replication protein A phosphorylation response differs between ataxia telangiectasia and normal human cells. Mol Cell Biol 1993; 13:7222-7231.

91 Zernik-Kobak M, Vasunia K, Connelly M, Anderson CW, Dixon K. Sites of UV-induced phosphorylation of the p34 subunit of replication protein A from HeLa cells. J Biol Chem 1997; 272:23896-23904.

92 Carty MP, Zernik-Kobak M, McGrath S, Dixon K. UV light-induced DNA synthesis arrest in HeLa cells is associated with changes in phosphorylation of human single-stranded DNA-binding protein. EMBOJ 1994; 13:2114-2123.

93 Fotedar R, Roberts JM. Cell cycle regulated phosphorylation of RPA-32 occurs within the replication initiation complex. EMBO J 1992; 11:2177-2187.

94 Liaw H, Lee D, Myung K. DNA-PK-dependent RPA2 hyperphosphorylation facilitates DNA repair and suppresses sister chromatid exchange. PLoS One 2011; 6:e21424. 
95 Binz SK, Sheehan AM, Wold MS. Replication protein A phosphorylation and the cellular response to DNA damage. DNA Repair (Amst) 2004; 3:1015-1024.

96 Olson E, Nievera CJ, Klimovich V, Fanning E, Wu X. RPA2 is a direct downstream target for ATR to regulate the S-phase checkpoint. J Biol Chem 2006; 281:39517-39533.

97 Vassin VM, Anantha RW, Sokolova E, Kanner S, Borowiec JA. Human RPA phosphorylation by ATR stimulates DNA synthesis and prevents ssDNA accumulation during DNA-replication stress. J Cell Sci 2009; 122:4070-4080.

98 Liu S, Opiyo SO, Manthey K, et al. Distinct roles for DNAPK, ATM and ATR in RPA phosphorylation and checkpoint activation in response to replication stress. Nucleic Acids Res 2012; 40:10780-10794.

99 Block WD, Yu Y, Lees-Miller SP. Phosphatidyl inositol 3-kinase-like serine/threonine protein kinases (PIKKs) are required for DNA damage-induced phosphorylation of the 32 $\mathrm{kDa}$ subunit of replication protein A at threonine 21. Nucleic Acids Res 2004; 32:997-1005.

100 Koivomagi M, Valk E, Venta R, et al. Cascades of multisite phosphorylation control Sicl destruction at the onset of $\mathrm{S}$ phase. Nature 2011; 480:128-131.

101 Anantha RW, Vassin VM, Borowiec JA. Sequential and synergistic modification of human RPA stimulates chromosomal DNA repair. J Biol Chem 2007; 282:35910-35923.

102 Vassin VM, Wold MS, Borowiec JA. Replication protein A (RPA) phosphorylation prevents RPA association with replication centers. Mol Cell Biol 2004; 24:1930-1943.

103 Anantha RW, Sokolova E, Borowiec JA. RPA phosphorylation facilitates mitotic exit in response to mitotic DNA damage. Proc Natl Acad Sci USA 2008; 105:12903-12908.

104 Murphy AK, Fitzgerald M, Ro T, et al. Phosphorylated RPA recruits PALB2 to stalled DNA replication forks to facilitate fork recovery. J Cell Biol 2014; 206:493-507.

105 Shi W, Feng Z, Zhang J, et al. The role of RPA2 phosphorylation in homologous recombination in response to replication arrest. Carcinogenesis 2010; 31:994-1002.

106 Lee DH, Pan Y, Kanner S, Sung P, Borowiec JA, Chowdhury D. A PP4 phosphatase complex dephosphorylates RPA2 to facilitate DNA repair via homologous recombination. Nat Struct Mol Biol 2010; 17:365-372.

107 Ashley AK, Shrivastav M, Nie J, et al. DNA-PK phosphorylation of RPA32 Ser4/Ser8 regulates replication stress checkpoint activation, fork restart, homologous recombination and mitotic catastrophe. DNA Repair (Amst) 2014; 21:131-139.

108 Vidal-Eychenie S, Decaillet C, Basbous J, Constantinou A. DNA structure-specific priming of ATR activation by DNAPKcs. J Cell Biol 2013; 202:421-429.

109 Reinhardt HC, Yaffe MB. Phospho-Ser/Thr-binding domains: navigating the cell cycle and DNA damage response. Nat Rev Mol Cell Biol 2013; 14:563-580.

110 Ciccia A, Elledge SJ. The DNA damage response: making it safe to play with knives. Mol Cell 2010; 40:179-204.

111 Polo SE, Jackson SP. Dynamics of DNA damage response proteins at DNA breaks: a focus on protein modifications. Genes Dev 2011; 25:409-433.

112 Patrick SM, Oakley GG, Dixon K, Turchi JJ. DNA damage induced hyperphosphorylation of replication protein A. 2. Characterization of DNA binding activity, protein interac- tions, and activity in DNA replication and repair. Biochemistry 2005; 44:8438-8448.

113 Oakley GG, Patrick SM, Yao J, Carty MP, Turchi JJ, Dixon K. RPA phosphorylation in mitosis alters DNA binding and protein-protein interactions. Biochemistry 2003; 42:3255-3264.

114 Binz SK, Lao Y, Lowry DF, Wold MS. The phosphorylation domain of the 32-kDa subunit of replication protein A (RPA) modulates RPA-DNA interactions. Evidence for an intersubunit interaction. J Biol Chem 2003; 278:35584-35591.

115 Serrano MA, Li Z, Dangeti M, et al. DNA-PK, ATM and ATR collaboratively regulate p53-RPA interaction to facilitate homologous recombination DNA repair. Oncogene 2013; 32:2452-2462.

116 Abramova NA, Russell J, Botchan M, Li R. Interaction between replication protein $\mathrm{A}$ and $\mathrm{p} 53$ is disrupted after UV damage in a DNA repair-dependent manner. Proc Natl Acad Sci USA 1997; 94:7186-7191.

117 Shao RG, Cao CX, Zhang H, Kohn KW, Wold MS, Pommier Y. Replication-mediated DNA damage by camptothecin induces phosphorylation of RPA by DNA-dependent protein kinase and dissociates RPA:DNA-PK complexes. EMBO J 1999; 18:1397-1406.

118 Yoo E, Kim BU, Lee SY, Cho CH, Chung JH, Lee CH. $53 \mathrm{BP} 1$ is associated with replication protein $\mathrm{A}$ and is required for RPA2 hyperphosphorylation following DNA damage. Oncogene 2005; 24:5423-5430.

119 Wu X, Yang Z, Liu Y, Zou Y. Preferential localization of hyperphosphorylated replication protein A to double-strand break repair and checkpoint complexes upon DNA damage. Biochem J 2005; 391:473-480.

120 Robison JG, Elliott J, Dixon K, Oakley GG. Replication protein A and the Mre11.Rad50.Nbs1 complex co-localize and interact at sites of stalled replication forks. $J$ Biol Chem 2004; 279:34802-34810.

$121 \mathrm{Wu}$ X, Shell SM, Zou Y. Interaction and colocalization of $\operatorname{Rad} 9 / \operatorname{Rad} 1 / H u s 1$ checkpoint complex with replication protein A in human cells. Oncogene 2005; 24:4728-4735.

122 Feng J, Wakeman T, Yong S, Wu X, Kornbluth S, Wang XF. Protein phosphatase 2A-dependent dephosphorylation of replication protein A is required for the repair of DNA breaks induced by replication stress. Mol Cell Biol 2009; 29:56965709.

123 Dou H, Huang C, Singh M, Carpenter PB, Yeh ET. Regulation of DNA repair through deSUMOylation and SUMOylation of replication protein A complex. Mol Cell 2010; 39:333-345.

124 Psakhye I, Jentsch S. Protein group modification and synergy in the SUMO pathway as exemplified in DNA repair. Cell 2012; 151:807-820.

125 Cremona CA, Sarangi P, Yang Y, Hang LE, Rahman S, Zhao $\mathrm{X}$. Extensive DNA damage-induced sumoylation contributes to replication and repair and acts in addition to the mec1 checkpoint. Mol Cell 2012; 45:422-432.

126 Burgess RC, Rahman S, Lisby M, Rothstein R, Zhao X. The Slx5-Slx8 complex affects sumoylation of DNA repair proteins and negatively regulates recombination. Mol Cell Biol 2007; 27:6153-6162.

127 Shima H, Suzuki H, Sun J, et al. Activation of the SUMO modification system is required for the accumulation of 
RAD51 at sites of DNA damage. J Cell Sci 2013; 126:52845292.

128 Guo Z, Kanjanapangka J, Liu N, et al. Sequential posttranslational modifications program FEN1 degradation during cell-cycle progression. Mol Cell 2012; 47:444-456.

129 Prudden J, Pebernard S, Raffa G, et al. SUMO-targeted ubiquitin ligases in genome stability. EMBO J 2007; 26:40894101.

130 Povlsen LK, Beli P, Wagner SA, et al. Systems-wide analysis of ubiquitylation dynamics reveals a key role for PAF15 ubiquitylation in DNA-damage bypass. Nat Cell Biol 2012; 14:1089-1098.

131 Chan SP, Kao DI, Tsai WY, Cheng SC. The Prp19p-associated complex in spliceosome activation. Science 2003; 302:279-282.

132 Song EJ, Werner SL, Neubauer J, et al. The Prp19 complex and the Usp4Sart3 deubiquitinating enzyme control reversible ubiquitination at the spliceosome. Genes Dev 2010; 24:1434-1447.

133 Zhang N, Kaur R, Lu X, Shen X, Li L, Legerski RJ. The Pso4 mRNA splicing and DNA repair complex interacts with WRN for processing of DNA interstrand cross-links. $J$ Biol Chem 2005; 280:40559-40567.

134 Zhang N, Kaur R, Akhter S, Legerski RJ. Cdc5L interacts with ATR and is required for the S-phase cell-cycle checkpoint. EMBO Rep 2009; 10:1029-1035.

135 Beck BD, Park SJ, Lee YJ, Roman Y, Hromas RA, Lee SH. Human Pso4 is a metnase (SETMAR)-binding partner that regulates metnase function in DNA repair. J Biol Chem 2008; 283:9023-9030.

136 Mahajan KN, Mitchell BS. Role of human Pso4 in mammalian DNA repair and association with terminal deoxynucleotidyl transferase. Proc Natl Acad Sci USA 2003; 100:1074610751.

137 Grote M, Wolf E, Will CL, et al. Molecular architecture of the human Prp19/CDC5L complex. Mol Cell Biol 2010; 30:2105-2119.

138 Wan L, Huang J. The PSO4 complex associates with RPA and modulates the activation of ATR. J Biol Chem 2014; 289:6619-6626.

139 Abbas M, Shanmugam I, Bsaili M, Hromas R, Shaheen M. The role of the human Psoralen 4 (hPso4) complex in replication stress and homologous recombination. $J$ Biol Chem 2014; 289:14009-14019.

140 Gong Z, Chen J. E3 ligase RFWD3 participates in replication checkpoint control. J Biol Chem 2011; 286:22308-22313.

141 Liu S, Chu J, Yucer N, et al. RING finger and WD repeat domain 3 (RFWD3) associates with replication protein A (RPA) and facilitates RPA-mediated DNA damage response. $J$ Biol Chem 2011; 286:22314-22322.

142 Davies AA, Huttner D, Daigaku Y, Chen S, Ulrich HD. Activation of ubiquitin-dependent DNA damage bypass is mediated by replication protein a. Mol Cell 2008; 29:625-636.

143 Jeong YT, Rossi M, Cermak L, et al. FBH1 promotes DNA double-strand breakage and apoptosis in response to DNA replication stress. J Cell Biol 2013; 200:141-149.

144 Galanty Y, Belotserkovskaya R, Coates J, Jackson SP. RNF4, a SUMO-targeted ubiquitin E3 ligase, promotes DNA double-strand break repair. Genes Dev 2012; 26:1179-1195.
145 Luo K, Zhang H, Wang L, Yuan J, Lou Z. Sumoylation of MDC1 is important for proper DNA damage response. EMBO J 2012; 31:3008-3019.

146 Guzzo CM, Berndsen CE, Zhu J, et al. RNF4-dependent hybrid SUMO-ubiquitin chains are signals for RAP80 and thereby mediate the recruitment of BRCA1 to sites of DNA damage. Sci Signal 2012; 5:ra88.

147 Vyas R, Kumar R, Clermont F, et al. RNF4 is required for DNA double-strand break repair in vivo. Cell Death Differ 2013; 20:490-502.

148 Yin Y, Seifert A, Chua JS, Maure JF, Golebiowski F, Hay RT. SUMO-targeted ubiquitin E3 ligase RNF4 is required for the response of human cells to DNA damage. Genes Dev 2012; 26:1196-1208.

149 Jackson SP, Durocher D. Regulation of DNA damage responses by ubiquitin and SUMO. Mol Cell 2013; 49:795807.

150 Panier S, Ichijima Y, Fradet-Turcotte A, et al. Tandem protein interaction modules organize the ubiquitin-dependent response to DNA double-strand breaks. Mol Cell 2012; 47:383395.

151 Fradet-Turcotte A, Canny MD, Escribano-Diaz C, et al. $53 \mathrm{BP} 1$ is a reader of the DNA-damage-induced H2A Lys 15 ubiquitin mark. Nature 2013; 499:50-54.

152 Chaudhuri J, Khuong C, Alt FW. Replication protein A interacts with AID to promote deamination of somatic hypermutation targets. Nature 2004; 430:992-998.

153 Brosh RM, Li JL, Kenny MK, et al. Replication protein A physically interacts with the Bloom's syndrome protein and stimulates its helicase activity. J Biol Chem 2000; 275:23500-23508.

154 Doherty KM, Sommers JA, Gray MD, et al. Physical and functional mapping of the replication protein a interaction domain of the werner and bloom syndrome helicases. $J$ Biol Chem 2005; 280:29494-29505.

155 Wong JM, Ionescu D, Ingles CJ. Interaction between BRCA2 and replication protein A is compromised by a cancer-predisposing mutation in BRCA2. Oncogene 2003; 22:28-33.

156 Bae KH, Kim HS, Bae SH, Kang HY, Brill S, Seo YS. Bimodal interaction between replication-protein A and Dna2 is critical for Dna2 function both in vivo and in vitro. Nucleic Acids Res 2003; 31:3006-3015.

$157 \mathrm{Kim} \mathrm{DH}$, Lee KH, Kim JH, et al. Enzymatic properties of the Caenorhabditis elegans Dna2 endonuclease/helicase and a species-specific interaction between RPA and Dna2. Nucleic Acids Res 2005; 33:1372-1383.

158 Shao RG, Cao CX, Zhang H, Kohn KW, Wold MS, Pommier Y. Replication-mediated DNA damage by camptothecin induces phosphorylation of RPA by DNA-dependent protein kinase and dissociates RPA:DNA-PK complexes. EMBO J 1999; 18:1397-1406.

159 Sparks JL, Kumar R, Singh M, Wold MS, Pandita TK, Burgers PM. Human exonuclease 5 is a novel sliding exonuclease required for genome stability. $J$ Biol Chem 2012; 287:4277342783.

160 Fujimoto M, Takaki E, Takii R, et al. RPA assists HSF1 access to nucleosomal DNA by recruiting histone chaperone FACT. Mol Cell 2012; 48:182-194.

161 VanDemark AP, Blanksma M, Ferris E, Heroux A, Hill CP, 
Formosa T. The structure of the yFACT Pob3-M domain, its interaction with the DNA replication factor RPA, and a potential role in nucleosome deposition. Mol Cell 2006; 22:363-374.

162 Gupta R, Sharma S, Sommers JA, Kenny MK, Cantor SB, Brosh RM Jr. FANCJ (BACH1) helicase forms DNA damage inducible foci with replication protein $\mathrm{A}$ and interacts physically and functionally with the single-stranded DNA-binding protein. Blood 2007; 110:2390-2398.

163 MacKay C, Toth R, Rouse J. Biochemical characterisation of the SWI/SNF family member HLTF. Biochem Biophys Res Commun 2009; 390:187-191.

164 Robison JG, Elliott J, Dixon K, Oakley GG. Replication protein A and the Mre11.Rad50.Nbs1 complex co-localize and interact at sites of stalled replication forks. $J$ Biol Chem 2004; 279:34802-34810.

165 Oakley GG, Tillison K, Opiyo Sa, Glanzer JG, Horn JM, Patrick SM. Physical interaction between replication protein A (RPA) and MRN: involvement of RPA2 phosphorylation and the N-terminus of RPA1. Biochemistry 2009; 48:7473-7481.

$166 \mathrm{Xu}$ X, Vaithiyalingam S, Glick GG, Mordes Da, Chazin WJ, Cortez D. The basic cleft of RPA70N binds multiple checkpoint proteins, including RAD9, to regulate ATR signaling. Mol Cell Biol 2008; 28:7345-7353.

167 Daniely Y, Borowiec JA. Formation of a complex between nucleolin and replication protein A after cell stress prevents initiation of DNA replication. J Cell Biol 2000; 149:799-810.

168 Dornreiter I, Erdile LF, Gilbert IU, von Winkler D, Kelly TJ, Fanning E. Interaction of DNA polymerase alpha-primase with cellular replication protein A and SV40 T antigen. EMBO J 1992; 11:769-776.

169 Li R, Botchan MR. The acidic transcriptional activation domains of VP16 and p53 bind the cellular replication protein A and stimulate in vitro BPV-1 DNA replication. Cell 1993; 73:1207-1221.

170 Dutta A, Ruppert JM, Aster JC, Winchester E. Inhibition of DNA replication factor RPA by p53. Nature 1993; 365:7982.

171 Wan L, Lou J, Xia Y, et al. hPrimpol1/CCDC111 is a human DNA primase-polymerase required for the maintenance of genome integrity. EMBO Rep 2013; 14:1104-1112.

172 Ellison V, Stillman B. Biochemical characterization of DNA damage checkpoint complexes: clamp loader and clamp complexes with specificity for 5' recessed DNA. PLoS Biol 2003; 1:E33.

173 Stauffer ME, Chazin WJ. Physical interaction between replication protein A and Rad51 promotes exchange on single-stranded DNA. J Biol Chem 2004; 279:25638-25645.

174 Hays SL, Firmenich AA, Massey P, Banerjee R, Berg P. Studies of the interaction between Rad52 protein and the yeast single-stranded DNA binding protein RPA. Mol Cell Biol 1998; 18:4400-4406.

175 Wang M, Park JS, Ishiai M, Hurwitz J, Lee SH. Species specificity of human RPA in simian virus 40 DNA replication lies in T-antigen-dependent RNA primer synthesis. Nucleic Acids Res 2000; 28:4742-4749.

176 Park CJ, Lee JH, Choi BS. Solution structure of the DNA-binding domain of RPA from Saccharomyces cerevisi$a e$ and its interaction with single-stranded DNA and SV40 T antigen. Nucleic Acids Res 2005; 33:4172-4181.

177 Unsal-Kacmaz K, Chastain PD, Qu PP, et al. The human Tim/Tipin complex coordinates an Intra-S checkpoint response to UV that slows replication fork displacement. $\mathrm{Mol}$ Cell Biol 2007; 27:3131-3142.

178 Nagelhus TA, Haug T, Singh KK, et al. A sequence in the $\mathrm{N}$-terminal region of human uracil-DNA glycosylase with homology to XPA interacts with the C-terminal part of the 34-kDa subunit of replication protein A. J Biol Chem 1997; 272:6561-6566.

179 Brosh RM, Orren DK, Nehlin JO, et al. Functional and physical interaction between WRN helicase and human replication protein A. J Biol Chem 1999; 274:18341-18350.

180 Machwe A, Lozada E, Wold MS, Li G-M, Orren DK. Molecular cooperation between the Werner syndrome protein and replication protein A in relation to replication fork blockage. J Biol Chem 2010; 286:3497-3508.

181 Shen JC, Lao Y, Kamath-Loeb A, Wold MS, Loeb LA. The $\mathrm{N}$-terminal domain of the large subunit of human replication protein A binds to Werner syndrome protein and stimulates helicase activity. Mech Ageing Dev 2003; 124:921-930.

182 Daughdrill GW, Buchko GW, Botuyan MV, et al. Chemical shift changes provide evidence for overlapping single-stranded DNA- and XPA-binding sites on the $70 \mathrm{kDa}$ subunit of human replication protein A. Nucleic Acids Res 2003; 31:4176-4183.

183 He Z, Henricksen LA, Wold MS, Ingles CJ. RPA involvement in the damage-recognition and incision steps of nucleotide excision repair. Nature 1995; 374:566-569.

184 Saijo M, Takedachi A, Tanaka K. Nucleotide excision repair by mutant xeroderma pigmentosum group A (XPA) proteins with deficiency in interaction with RPA. J Biol Chem 2011; 286:5476-5483.

185 de Laat WL, Appeldoorn E, Sugasawa K, Weterings E, Jaspers NG, Hoeijmakers JH. DNA-binding polarity of human replication protein A positions nucleases in nucleotide excision repair. Genes Dev 1998; 12:2598-2609.

186 Matsunaga T, Park CH, Bessho T, Mu D, Sancar A. Replication protein A confers structure-specific endonuclease activities to the XPF-ERCC1 and XPG subunits of human DNA repair excision nuclease. J Biol Chem 1996; 271:1104711050 .

187 Bessho T, Sancar A, Thompson LH, Thelen MP. Reconstitution of human excision nuclease with recombinant XPF-ERCC1 complex. J Biol Chem 1997; 272:3833-3837.

188 Fisher LA, Bessho M, Wakasugi M, Matsunaga T, Bessho T. Role of interaction of XPF with RPA in nucleotide excision repair. J Mol Biol 2011; 413:337-346. 